\title{
A Comparative Study of MPC and Economic MPC of Wind Energy Conversion Systems
}

\author{
Jinghan Cui ${ }^{1,2}$, Su Liu ${ }^{2}$, Jinfeng Liu ${ }^{2, *}$ and Xiangjie Liu ${ }^{1}$ \\ 1 The State Key Laboratory of Alternate Electrical Power System with Renewable Energy Sources, \\ North China Electric Power University, Beijing 102206, China; jinghan@ualberta.ca (J.C.); \\ liuxj@ncepu.edu.cn (X.L.) \\ 2 Department of Chemical \& Materials Engineering, University of Alberta, Edmonton, AB T6G 1H9, Canada; \\ su7@ualberta.ca \\ * Correspondence: jinfeng@ualberta.ca; Tel.: +1-780-492-1317
}

Received: 19 October 2018; Accepted: 7 November 2018; Published: 12 November 2018

check for updates

\begin{abstract}
In this work, we perform a comprehensive comparative study of two advanced control algorithms-the classical tracking model predictive control (MPC) and economic MPC (EMPC)—in the optimal operation of wind energy conversion systems (WECSs). A typical $5 \mathrm{MW}$ wind turbine is considered in this work. The tracking MPC is designed to track steady-state optimal operating reference trajectories determined using a maximum power point tracking (MPPT) algorithm. In the design of the tracking MPC, the entire operating region of the wind turbine is divided into four subregions depending on the wind speed. The tracking MPC tracks different optimal reference trajectories determined by the MPPT algorithm in these subregions. In the designed EMPC, a uniform economic cost function is used for the entire operating region and the division of the operating region into subregions is not needed. Two common economic performance indices of WECSs are considered in the design of the economic cost function for EMPC. The relation between the two economic performance indices and the implications of the relation on EMPC performance are also investigated. Extensive simulations are performed to show the advantages and disadvantages of the two control algorithms under different conditions. It is found that when the near future wind speed can be predicted and used in control, EMPC can improve the energy utilization by about $2 \%$ and reduce the operating cost by about $30 \%$ compared to classical tracking MPC, especially when the wind speed varies such that the tracking MPC switches between operating subregions. It is also found that uncertainty in information (e.g., future wind speed, measurement noise in wind speed) may deteriorate the performance of EMPC.
\end{abstract}

Keywords: renewable energy; predictive control; wind turbine; economic optimization; nonlinear systems

\section{Introduction}

Renewable energy generation technologies, like wind energy conversion systems (WECS), have been widely adopted globally. In a recent report of the National Renewable Energy Laboratory (NREL), for example, the State of Alaska Legislature in 2010 adopted the goal of supplying 50\% of Alaska energy needs from renewable energy sources by 2025 [1]. Among various modern renewable energy resources, wind energy accounts for the largest portion and is anticipated to maintain steady growth in the coming years.

It is well known that the control system of a WECS plays a very important role in balancing the efficiency of energy generation and structural fatigue of the WECS. In a typical tracking control design, a WECS has two operating modes, i.e., partial load mode and full load mode. When a WECS is operated in the partial load mode, a typical control objective is to adjust the generator speed to 
capture as much energy as possible from the wind; when the WECS is operated in the full load mode, the typical control objective is to regulate the blade pitch angle to maintain both the output power and the generator speed at their rated values to ensure the safety of the equipment [2]. The operation of a WECS may switch between these two operating modes frequently due to the variation of wind speed. This poses great challenges in the controller design for WECSs.

In the literature, many control strategies have been proposed for the control of WECSs with the purpose of either maximizing wind energy capture or maintaining the system at rated power. When a WECS operates in partial load mode, the maximum power point tracking (MPPT) is one of the most effective approaches for extracting energy from wind. Existing research studies primarily focus on three MPPT algorithms, namely, tip speed ratio (TSR) control, hill-climb search (HCS) control, and power signal feedback control [3,4]. In these algorithms, the optimal steady-state reference trajectories are calculated. These reference trajectories are then sent to the feedback control layer. The main objective of the feedback control layer is to drive a WECS to track the optimal reference trajectories. In the feedback control layer, different control algorithms have been explored including the classical proportional integral (PI) control [5,6], linear quadratic Gaussian (LQG) approach [7,8], robust control [9,10], and model predictive control (MPC) [11-15]. Among these algorithms, MPC has become more and more popular because of its ability to account for state and input constraints as well as optimality considerations explicitly in the evaluation of control actions.

While the framework of MPPT and MPC has been successful, it primarily focuses on tracking the optimal operating references which are different for different operating modes (partial load and full load). The transition between the operating modes (which may be frequent) are not explicitly considered, which may lead to loss of control performance. In recent years, a generalized form of MPC—economic MPC (EMPC)— has been developed and attracted significant attention. In EMPC, the separation between operating reference optimization (e.g., MPPT) and reference tracking is removed; and real-time operating reference optimization and feedback control are integrated into one optimal control framework [16-20]. EMPC uses the economic index directly as the cost function for online optimization and has been demonstrated to provide improved economic performance than the classical tracking MPC in different applications [21-23]. In [24,25], EMPC were applied to the control of wind turbines. However, these two papers did not present a detailed analysis for the entire operating region. In particular, the transition between the operating modes were not considered. Moreover, information uncertainty and the impact of prediction horizon were not taken into consideration explicitly.

In this paper, we perform a comprehensive comparison of the classical tracking MPC and EMPC for WECSs. Specifically, we consider a typical wind turbine in this work. Both operating modes of the wind turbine are considered. The entire operating range of the wind turbine is divided into four subregions depending on the wind speed. The tracking MPC tracks different operating references in these subregions and the operating references are determined by an MPPT algorithm. In the design of EMPC, one single economic cost function is used for the entire operating region. Two common performance indices for wind turbines are used in the design of the economic cost for EMPC. The relation between the two performance indices is also investigated. The implications of the relation on EMPC performance and behaviors are also discussed. Extensive simulations are performed to study the advantages and disadvantages of the tracking MPC and the EMPCs with the two different cost functions under perfect information and uncertain information scenarios. It is found that when the near future wind speed can be predicted and used in control, EMPC can improve the energy utilization and reduce the operating cost compared to the tracking MPC, especially when the wind speed varies such that the tracking MPC switches between operating subregions. It is also found that uncertainty in information (e.g., future wind speed, measurement noise in wind speed) may deteriorate the performance of EMPC.

The main objective of this paper is to compare classical tracking MPC and EMPC for WECSs. The rest of the paper is structured as follows: In Section 2, a description of the WECS and the nonlinear 
model used for controller design are given. In Section 3, a detailed description of the controllers design are proposed. Section 4 shows detailed simulations and analysis on the WECS under two controllers. Finally, Section 5 concludes the paper.

\section{Wind Energy Conversion System Description}

The WECS consists of a series of operating units including the wind turbine, the drivetrain shaft and the electric generator. A schematic of the WECS is shown in Figure 1. In the WECS, the kinetic energy in the wind is first captured by the wind turbine in the form of mechanical energy, which is then transported through the drivetrain shaft, and is transformed to electrical energy in the generator before it is finally delivered to the grid. The model considered is based on [26].

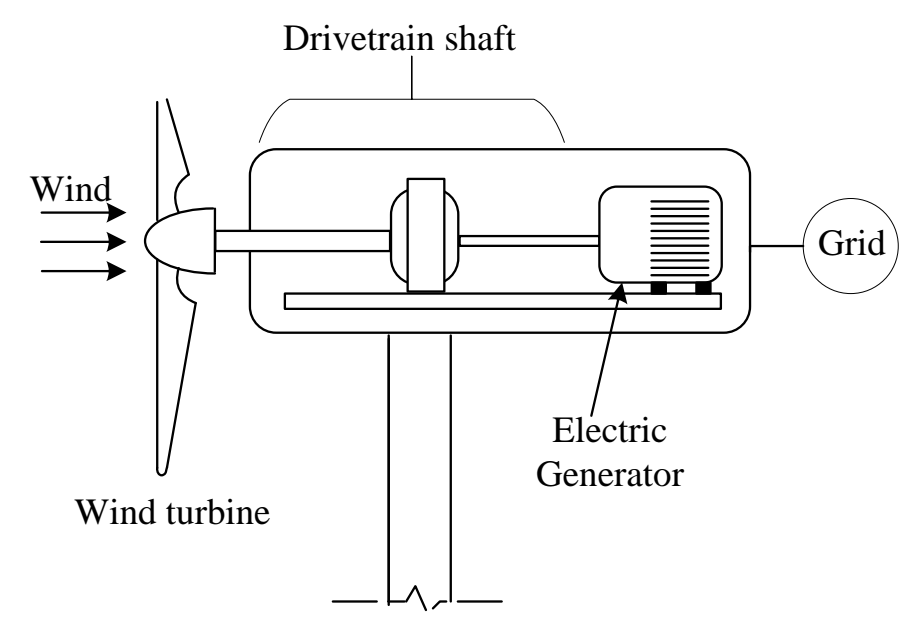

Figure 1. Schematic of the WECS.

\subsection{Wind Turbine}

The wind turbine rotor interacts with the wind stream, resulting in a behavior named aerodynamics. In addition, the aerodynamic power, which means the kinetic energy of wind in a unit length of time, depends on the wind speed on the rotor, the pitch angle and angular velocity of the rotor. The aerodynamic power $P_{a}$ extracted by the wind turbine can be described as [26]:

$$
P_{a}=\frac{1}{2} \rho \pi R^{2} v^{3} C_{p}(\lambda, \beta),
$$

where $\rho$ is the air density, $R$ is the rotor radius, $v$ is the rotor wind speed, $\beta$ is the pitch angle of the rotor blade, $\lambda$ is the ratio between the peripheral blade speed and the wind speed:

$$
\lambda=\frac{\omega_{a} R}{v},
$$

where $\omega_{a}$ is the rotor angular velocity. The aerodynamic power coefficient $C_{p}(\lambda, \beta)$, describing the power extraction efficiency of a wind turbine, is modeled as follows [11]:

$$
C_{p}=0.5176\left(116 / \lambda_{i}-0.4 \beta-5\right) e^{-21 / \lambda_{i}}+0.0068 \lambda,
$$

where $\lambda_{i}$ is determined using

$$
\frac{1}{\lambda_{i}}=\frac{1}{\lambda+0.08 \beta}-\frac{0.035}{\beta^{3}+1} .
$$


A graph of the aerodynamic power coefficient $C_{p}(\lambda, \beta)$ is shown in Figure 2. As shown in the figure, the maximum aerodynamic power coefficient can be achieved by appropriately tuning $\lambda$ and $\beta$. Let us denote the corresponding $\lambda$ and $\beta$ that give the maximum $C_{p}$ as $\lambda_{\text {opt }}$ and $\beta_{\text {opt }}$; that is,

$$
\left(\lambda_{\text {opt }}, \beta_{\text {opt }}\right)=\arg \max _{\lambda, \beta} C_{p}(\lambda, \beta) .
$$

It is considered that the angular velocity of rotor $\omega_{a}$ is subject to the following constraint:

$$
\omega_{a, \text { in }} \leq \omega_{a}(\tau) \leq \omega_{a, \text { rated }}
$$

where $\omega_{a, \text { in }}$ is the cut-in rotor speed and $\omega_{a, \text { rated }}$ is the rated rotor speed.

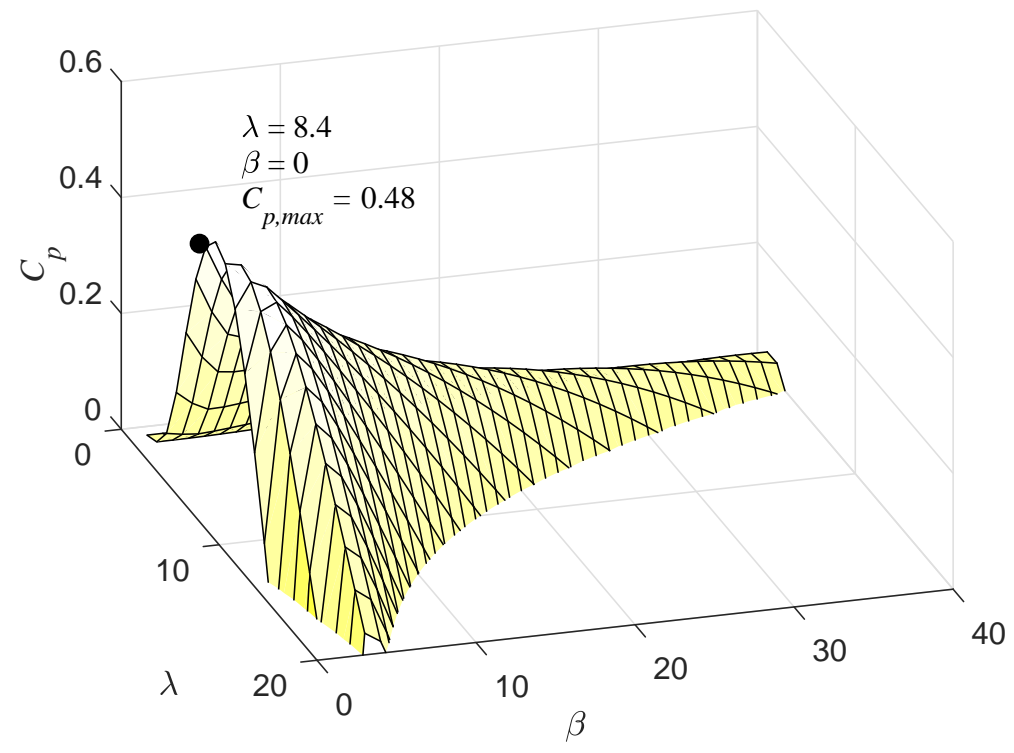

Figure 2. Power coefficient surface for WECS.

The pitch angle $\beta$ is adjusted by a pitch angle actuator. The dynamics of the pitch angle $\beta$ is modeled as the following second-order differential equation:

$$
\ddot{\beta}=-w_{n}^{2} \beta-2 \zeta w_{n} \dot{\beta}+w_{n}^{2} \beta_{r e f},
$$

where $\beta_{\text {ref }}$ is the desired pitch angle and is the manipulated input of the pitch angle actuator, $\beta$ is the actual pitch angle, $w_{n}$ is the natural frequency of the pitch actuator, and $\xi$ is the damping constant of the pitch actuator. In the MPC design considered in this work, $\beta_{\text {ref }}$ will be one of the manipulated inputs.

The pitch angle is subject to the following constraints:

$$
\begin{aligned}
& \beta_{\text {min }} \leq \beta(\tau) \leq \beta_{\text {max }}, \\
& \dot{\beta}_{\text {min }} \leq \dot{\beta}(\tau) \leq \dot{\beta}_{\text {max }},
\end{aligned}
$$

where $\beta_{\min }$ and $\beta_{\max }$ denote respectively the minimum and maximum values that the pitch angle may take $\dot{\beta}_{\min }$ and $\dot{\beta}_{\max }$ denote, respectively, the minimum and maximum pitch angular speeds.

\subsection{Drivetrain Shaft}

The generator receives power from the wind turbine through a drivetrain shaft system. The drivetrain shaft includes a low-speed shaft, a high-speed shaft, and a gearbox. The low-speed shaft is considered to be flexible while the high-speed shaft is considered to be rigid. Stiffness and damping 
of the low-speed shaft are modeled as one spring and one damper. Based on these assumptions, a two-mass drivetrain model can be developed as shown below [26]:

$$
\begin{gathered}
J_{a} \dot{\omega}_{a}=T_{a}-k_{s} \theta-d_{s} \dot{\theta}, \\
T_{a}=\frac{P_{a}}{\omega_{a}}=\frac{1}{2 \omega_{a}} \rho \pi R^{2} v^{3} C_{p}(\lambda, \beta), \\
J_{g} \dot{\omega}_{g}=\frac{k_{s} \theta}{N_{g}}+\frac{d_{s} \dot{\theta}}{N_{g}}-T_{g}, \\
\dot{\theta}=\omega_{a}-\frac{\omega_{g}}{N_{g}},
\end{gathered}
$$

where $J_{a}$ and $J_{g}$ are the inertia of the rotor and the generator, respectively. $T_{a}$ is the aerodynamic torque. $k_{s}$ and $d_{s}$ are the stiffness and damping coefficients of the low-speed shaft. $\theta$ stands for the shaft twist angle. $T_{g}$ is the generator torque and $\omega_{g}$ is the generator angular velocity. $N_{g}$ is the gear ratio. A schematic of the drivetrain shaft system is shown in Figure 3.

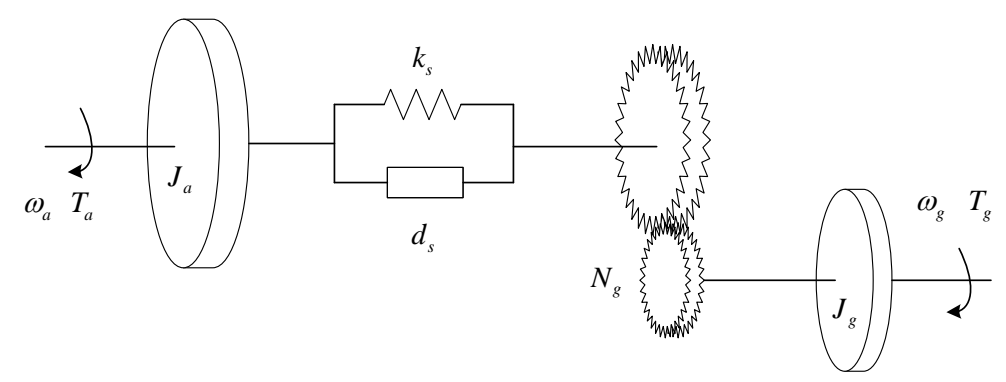

Figure 3. Drivetrain shaft system of WECS.

\subsection{Electric Generator}

The electric generator exerts a counter torque $T_{g}$ on the drivetrain shaft, its dynamics can be described as follows:

$$
\dot{T}_{g}=-\frac{1}{\tau_{g}} T_{g}+\frac{1}{\tau_{g}} T_{g, r e f},
$$

where $T_{g, r e f}$ is a manipulated input variable and denotes the desired torque values, $T_{g}$ is the actual generator torque. $\tau_{g}$ is the time constant of the generator.

The operation of the generator is subject to the following constraints:

$$
\begin{gathered}
0 \leq T_{g}(\tau) \leq T_{g, \text { rated }}, \\
\dot{T}_{g, \min } \leq \dot{T}_{g}(\tau) \leq \dot{T}_{g, \text { max }},
\end{gathered}
$$

where $T_{g, \text { rated }}$ is the rated generator torque. $\dot{T}_{g, \min }$ and $\dot{T}_{g, \max }$ denote respectively the minimum and maximum generator torque speeds.

The electrical power converted from the mechanical power is modeled as follows:

$$
P_{e}=\eta T_{g} \omega_{g}
$$

where $\eta$ is the efficiency of power conversion. The electrical power should satisfy the following constraint

$$
0 \leq P_{e}(\tau) \leq P_{e, \text { rated }}
$$

where $P_{e, \text { rated }}$ is the rated power. 


\subsection{State-Space Representation}

Defining a set of state variables $x=\left[\begin{array}{llllll}\omega_{a} & \omega_{g} & \theta & T_{g} & \beta & \dot{\beta}\end{array}\right]^{T}$, input variables $u=\left[\begin{array}{cc}T_{g, r e f} & \beta_{\text {ref }}\end{array}\right]^{T}$, the dynamics of the state variables can be written in the following compact form based on the modeling equations described in Sections 2.1-2.3:

$$
\dot{x}=f(x, u, v),
$$

where the wind speed $v$ is an disturbance input to the system. Figure 4 shows the block diagram of the model, and $T_{g, r e f}$ and $\beta_{\text {ref }}$ are manipulated inputs of the system. The parameters of the model used in this work are reported in Table 1 [27].

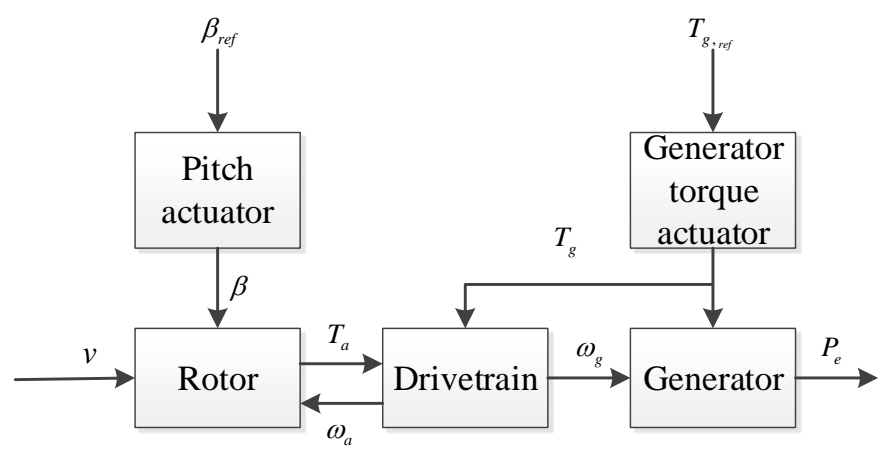

Figure 4. Block diagram of the WECS.

Table 1. Model parameters for $5 \mathrm{MW}$ wind turbine [27].

\begin{tabular}{|c|c|c|}
\hline Parameters & Values & Definitions \\
\hline$P_{e, \text { rated }}$ & 5 & Rated power (MW) \\
\hline$T_{g, \text { rated }}$ & $43,093.55$ & Rated generator torque $(\mathrm{N} \cdot \mathrm{m})$ \\
\hline$\omega_{a, \text { rated }}$ & 12.1 & Rated rotor speed (rpm) \\
\hline$\omega_{a, i n}$ & 6.9 & Cut-in rotor speed (rpm) \\
\hline$v_{i n}$ & 3 & Cut-in wind speed (m/s) \\
\hline$v_{2}$ & 5.4 & Boundary wind speed $(\mathrm{m} / \mathrm{s})$ \\
\hline$v_{3}$ & 9.5 & Boundary wind speed $(\mathrm{m} / \mathrm{s})$ \\
\hline$v_{\text {rated }}$ & 11.2 & Rated wind speed (m/s) \\
\hline$v_{\text {out }}$ & 25 & Cut-out wind speed $(\mathrm{m} / \mathrm{s})$ \\
\hline$\rho$ & 1.23 & Air density $\left(\mathrm{kg} / \mathrm{m}^{3}\right)$ \\
\hline$R$ & 63 & Blade radius $(\mathrm{m})$ \\
\hline$\lambda_{o p t}$ & 8.4 & Optimal tip speed ratio \\
\hline$\beta_{o p t}$ & 0 & Optimal blade pitch \\
\hline$C_{p, \max }$ & 0.48 & Peak power coefficient \\
\hline$N_{g}$ & 97 & Gear ratio \\
\hline$J_{a}$ & $3.54 \times 10^{7}$ & Rotor inertia $\left(\mathrm{kg} \cdot \mathrm{m}^{2}\right)$ \\
\hline$J_{g}$ & 534.116 & Generator inertia $\left(\mathrm{kg} \cdot \mathrm{m}^{2}\right)$ \\
\hline$k_{s}$ & $8.676 \times 10^{8}$ & Drivetrain shaft stiffness $(\mathrm{N} \cdot \mathrm{m} / \mathrm{rad})$ \\
\hline$d_{s}$ & $6.215 \times 10^{6}$ & Drivetrain damping coefficients $(\mathrm{N} \cdot \mathrm{m} /(\mathrm{rad} / \mathrm{s}))$ \\
\hline$\tau_{g}$ & 0.1 & Time constant of generator torque actuator (s) \\
\hline $\begin{array}{c}0 \\
w_{n}\end{array}$ & 0.88 & Natural frequency of pitch actuator $(\mathrm{rad} / \mathrm{s})$ \\
\hline$\xi$ & 0.1 & Damping of pitch actuator \\
\hline$\beta_{\max }$ & 90 & Maximum blade pitch \\
\hline$\beta_{\min }$ & 0 & Minimum blade pitch \\
\hline$\dot{\beta}_{\max }$ & 8 & Maximum blade pitch rate \\
\hline$\dot{\beta}_{\min }$ & -8 & Minimum blade pitch rate \\
\hline$\dot{T} g_{\text {max }}$ & 15,000 & Maximum generator torque rate $(\mathrm{N} \cdot \mathrm{m} / \mathrm{s})$ \\
\hline$\dot{T} g_{\text {min }}$ & $-15,000$ & Minimum generator torque rate $(\mathrm{N} \cdot \mathrm{m} / \mathrm{s})$ \\
\hline$\eta$ & $94.4 \%$ & Generator efficiency \\
\hline
\end{tabular}




\section{Model Predictive Control Strategies}

The primary objective of the WECS is to maximize wind power capture while protecting the operating units. For a WECS, there are many constraints that should be satisfied to ensure equipment safety of the system. Specifically, constraints Equations (7), (8) and (15) are considered as hard constraints while Equations (5), (14) and (17) can be treated as soft constraints that may be relaxed for sufficiently short time periods.

\subsection{Classical Tracking MPC}

\subsubsection{Steady-State Target Calculation}

In this section, we calculate the optimal steady-state targets for the rotor speed $\omega_{a}$, blade pitch angle $\beta$ and generator torque $T_{g}$. At a steady-state, we have

$$
P_{e}=\eta P_{a}=\frac{1}{2} \eta \rho \pi R^{2} v^{3} C_{p}(\lambda, \beta) .
$$

Due to less than perfect efficiency, the generator is only able to convert some of the mechanical power to electrical power [26]. Thus, the objective of maximizing the steady-state electric power $P_{e}$ at a given wind speed $v$ is equivalent to maximizing the aerodynamic power coefficient $C_{p}$. Note that the dynamics of the generator torque actuator and pitch angle actuator disappear at steady-state conditions. Therefore, we can use the following steady-state optimization problem to find the optimal steady-state operating target:

$$
\begin{gathered}
C_{p, \max }(v)=\max _{\beta, \lambda, \omega_{a}, T_{g}} C_{p}(\lambda, \beta), \\
\text { s.t. } \lambda=\frac{\omega_{a} R}{v}, \\
\frac{1}{2 \omega_{a}} \rho \pi R^{2} v^{3} C_{p}=T_{g} N_{g}, \\
\omega_{a, i n} \leq \omega_{a}(\tau) \leq \omega_{a, \text { rated }} \\
\beta_{\min } \leq \beta(\tau) \leq \beta_{\max } \\
0 \leq T_{g}(\tau) \leq T_{g, \text { rated }} .
\end{gathered}
$$

The above steady-state optimization is a parametric optimization depending on the wind speed $v$. The solution is shown in Figure 5 where the entire operating region is divided into four regions with $v_{\text {in }}$, i.e., the cut-in wind speed for WECS, $v_{2}, v_{3}$ and $v_{\text {rated }}$ as a boundary.

Region IV: When the wind speed is over the rated value (i.e., $v \geq v_{\text {rated }}$ ), both the rotor speed and generator torque reaches their upper bound. That is:

$$
\begin{aligned}
& \omega_{a}^{r e f}(v):=\omega_{a, \text { rated }} \\
& T_{g}^{r e f}(v):=T_{g, \text { rated }}
\end{aligned}
$$

WECS keeps the electric power $P_{e}$ at its rated value by changing the blade pitch angle as follows:

$$
\beta^{\text {ref }}(v):=\left\{\beta \mid P_{e, \text { rated }}=\frac{1}{2} \eta \rho \pi R^{2} v^{3} C_{p}\left(\frac{\omega_{a, \text { rated }} R}{v}, \beta\right)\right\}
$$

When the wind speed is below the rated value, the WECS operates in the partial load region which is divided into three subregions, namely, I, II, III as shown in Figure 5. 

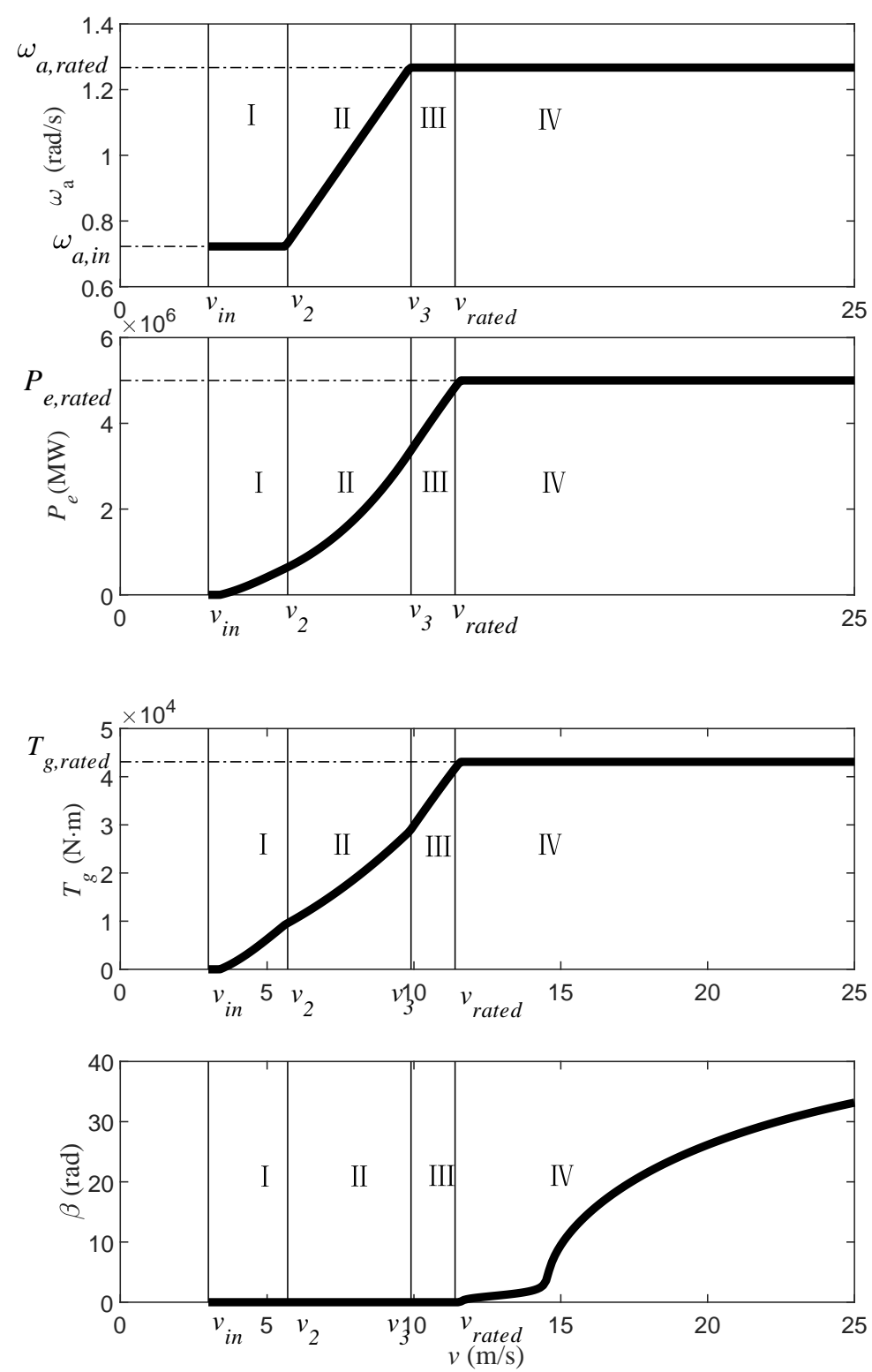

Figure 5. Optimal steady-state targets of the rotor speed $\left(\omega_{a}\right)$, electric power $\left(P_{e}\right)$, generator torque $\left(T_{g}\right)$, pitch angle $(\beta)$, under varying wind speed $v$.

Region III: When the wind speed is below the rated value and over the wind speed $v_{3}$ (i.e., $v_{3} \leq v<v_{\text {rated }}$ ), where

$$
v_{3}=\frac{\omega_{a, \text { rated }} R}{\lambda_{\text {opt }}},
$$

only the rotor speed reaches its upper bound, that is,

$$
\omega_{a}^{r e f}(v):=\omega_{a, r a t e d}
$$

The pitch angle is fixed at its optimal value (i.e., $\beta_{o p t}$ ), and the WECS maximizes electric power $P_{e}$ by changing the generator torque as follows:

$$
T_{g}^{r e f}(v):=\frac{1}{2 \omega_{a, \text { rated }} N_{g}} \rho \pi R^{2} v^{3} C_{p}\left(\frac{\omega_{a, r a t e d} R}{v}, 0\right) .
$$


The classical MPC strategy taken in this work assumes keeping the pitch at its optimal value $\beta_{\text {opt }}$ before the electrical power reaches its rated value:

$$
\beta^{r e f}(v):=\beta_{o p t} .
$$

Region II: When the wind speed is below the wind speed $v_{3}$ and over $v_{2}$ (i.e., $v_{2} \leq v<v_{3}$ ), where

$$
v_{2}=\frac{\omega_{a, i n} R}{\lambda_{\text {opt }}}
$$

It is expected to maximize wind power capture by maintaining WECS operating at the optimal power coefficient all the time. Previous research results primarily focus on the TSR control in this region, one of the conventional MPPT algorithms. Then, the optimal steady-state is readily obtained as [11]:

$$
\begin{gathered}
\omega_{a}^{r e f}(v):=\frac{\lambda_{o p t} v}{R}, \\
T_{g}^{r e f}(v):=\left\{T_{g} \mid \frac{1}{2} \rho \pi R^{2} v^{3} C_{p, \max }=N_{g} \frac{\lambda_{o p t} v}{R} T_{g}^{r e f}\right\}, \\
\beta^{r e f}(v):=\beta_{o p t} .
\end{gathered}
$$

These references in region III and II are also consistent with the optimal steady-state operating target obtained using Equation (19) in which only constraint Equation (5) is active in region III.

Region I: When the wind speed is between the cut-in wind speed $v_{i n}$ and wind speed $v_{2}$ (i.e., $v_{\text {in }}<v<v_{2}$ ), the rotor angular velocity $\omega_{a}$ is at its lowest allowed value,

$$
\omega_{a}^{r e f}(v):=\omega_{a, i n}
$$

and the $T_{g}$ reference can be obtained as follows:

$$
T_{g}^{r e f}(v):=\frac{1}{2 \omega_{a, i n} N_{g}} \rho \pi R^{2} v^{3} C_{p}\left(\frac{\omega_{a, i n} R}{v}, 0\right) .
$$

In this region, the reference of the pitch angle will be set at the optimal value:

$$
\beta^{r e f}(v):=\beta_{o p t}
$$

To sum up, the optimal reference rotor angular velocity $\omega_{a}^{*}$, pitch angle $\beta^{*}$ and the generator torque $T_{g}^{*}$ in MPC design according to the above discussion are as follows:

$$
\begin{aligned}
& \omega_{a}^{*}=\left\{\begin{array}{l}
\omega_{a, i n}, \quad \text { if } v_{\text {in }} \leq v \leq v_{2} \\
\frac{\lambda_{o p t} v}{R}, \quad \text { if } v_{2}<v \leq v_{\text {rated }} \\
\omega_{a, \text { rated }}, \quad \text { if } v>v_{\text {rated }}
\end{array}\right. \\
& \beta^{*}=\left\{\begin{array}{l}
\beta_{\text {opt, }}, \text { if } v \leq v_{\text {rated }} \\
\left\{\beta \mid P_{e, \text { rated }}=\frac{1}{2} \eta \rho \pi R^{2} v^{3} C_{p}\left(\frac{\omega_{a, \text { rated }} R}{v}, \beta\right)\right\}, \quad \text { if } v>v_{\text {rated }}
\end{array}\right. \\
& T_{g}^{*}=\left\{\begin{array}{l}
\frac{1}{2 \omega_{a, i n} N_{g}} \rho \pi R^{2} v^{3} C_{p}\left(\frac{\omega_{a, i n} R}{v}, 0\right), \quad \text { if } v_{\text {in }} \leq v \leq v_{2} \\
\left\{T_{g} \mid \frac{1}{2} \rho \pi R^{2} v^{3} C_{p, \text { max }}=N_{g} \frac{\lambda_{\text {opt }} v}{R} T_{g}^{r e f}\right\}, \quad \text { if } v_{2}<v \leq v_{3} \\
\frac{1}{2 \omega_{a, \text { rated }} N_{g}} \rho \pi R^{2} v^{3} C_{p}\left(\frac{\omega_{a, \text { rated }} R}{v}, 0\right), \quad \text { if } v_{3}<v \leq v_{\text {rated }} \\
T_{g, \text { rated }}, \quad \text { if } v>v_{\text {rated }} .
\end{array}\right.
\end{aligned}
$$


In the classical tracking MPC design, the MPC will track the three reference trajectories above depending on the wind speed.

\subsubsection{Tracking MPC Formulation}

The classical tracking MPC for WECS is based on tracking the wind dependent reference trajectories, while minimizing structural fatigue. As stated above, there are different control objectives for different operating regions. The classical tracking MPC achieves this through changing the reference. As for the state constraints of WECS, we will incorporate both hard constraints and soft constraints in the optimization problem. At a sampling time $t_{k}$, the MPC optimization problem for the WECS, under both partial load region and full load region is formulated as follows:

$$
\begin{gathered}
\min _{u(\tau) \in S(\Delta t), \varepsilon_{P}, \varepsilon_{\omega}, \varepsilon_{T}} \int_{t_{k}}^{t_{k}+N}\left(F_{M P C}(\tilde{x}(\tau), u(\tau), v(\tau))+F_{S}\left(\varepsilon_{P}, \varepsilon_{\omega}, \varepsilon_{T}\right)\right) d \tau, \\
\text { s.t. } \dot{\tilde{x}}(\tau)=f(\tilde{x}(\tau), u(\tau), v(\tau)), \\
\tilde{x}\left(t_{k}\right)=x\left(t_{k}\right), \\
0 \leq P_{e}(\tau) \leq P_{e, \text { rated }}+\varepsilon_{P}, \\
\omega_{a, \text { in }}-\varepsilon_{\omega} \leq \omega_{a}(\tau) \leq \omega_{a, \text { rated }}+\varepsilon_{\omega}, \\
0 \leq T_{g}(\tau) \leq T_{g, \text { rated }}+\varepsilon_{T}, \\
\beta_{\min } \leq \beta(\tau) \leq \beta_{\max } \\
\dot{T}_{g, \min } \leq \dot{T}_{g}(\tau) \leq \dot{T}_{g, \text { max }} \\
\dot{\beta}_{\min } \leq \dot{\beta}(\tau) \leq \dot{\beta}_{\max },
\end{gathered}
$$

where $S(\triangle t)$ denotes the family of continuous piece-wise functions with sampling time $\triangle t$. $N$ is the predictive horizon. $F_{M P C}(\tilde{x}(\tau), u(\tau), v(\tau))$ is the tracking objective function. $F_{S}\left(\varepsilon_{P}, \varepsilon_{\omega}, \varepsilon_{T}\right)$ is the punishment on slack variables. $\tilde{x}(\tau)$ is the predicted future state trajectory of the WECS. Equation (33b) is the nonlinear state-space representation of the WECS in Equation (18). $x\left(t_{k}\right)$ in Equation (33c) is the initial condition at time $t_{k}$. Equation $(33 \mathrm{~d}-\mathrm{h})$ are the output constraints and state constraints.

The tracking objective function is chosen as:

$$
\begin{aligned}
F_{M P C}(x(\tau), u(\tau), v(\tau)) & =q_{1}^{M P C}\left(\omega_{a}(\tau)-\omega_{a}^{*}(v)\right)^{2}+q_{2}^{M P C}\left(T_{g}(\tau)-T_{g}^{*}(v)\right)^{2} \\
& +q_{3}^{M P C}\left(\beta(\tau)-\beta^{*}(v)\right)^{2}+r^{M P C} \dot{\theta}^{2}(\tau)
\end{aligned}
$$

where $q_{1}^{M P C}, q_{2}^{M P C}, q_{3}^{M P C}, r^{M P C}$ are weights. The first three terms account for wind power capture while the last term of state change rate reflects the structural fatigue of the system. $\omega_{a}^{*}(v), T_{g}^{*}(v)$, $\beta^{*}(v)$ are the reference trajectories described in Equation (32).

The slack variables $\varepsilon_{P}, \varepsilon_{\omega}, \varepsilon_{T}$ are decision variables associated to the degree of violation of the corresponding constraints. We choose to penalize the slack variables using the quadratic form:

$$
F_{S}\left(\varepsilon_{P}, \varepsilon_{\omega}, \varepsilon_{T}\right)=r^{s}\left(\varepsilon_{P}^{2}+\varepsilon_{\omega}^{2}+\varepsilon_{T}^{2}\right),
$$

where $r^{s}$ is a penalty of the slack variables.

As for the constraints, Equation (33d-f) mean that the system should remain operating at the rated values when wind speed is over the rated value, while temporary violation of these constraints are acceptable. Treating these constraints as soft constraints makes the MPC optimization problem much easier to solve and may lead to improved closed-loop performance. Equation (33g) is a constraint on 
the blade pitch angle and constraints of Equation $(33 \mathrm{~h}, \mathrm{i})$ impose constraints on the increasing rate of blade pitch angle and the generator torque.

The controller is evaluated at discrete time instants $t_{k}=t_{0}+k \Delta t, k=0,1 \ldots$, with $t_{0}$ the initial time and $\Delta t$ the sampling time. If we denote the optimal solution to optimization problem Equation (33) as $u_{M P C}^{*}\left(t \mid t_{k}\right)$, only the first step value of $u_{M P C}^{*}\left(t \mid t_{k}\right)$ is applied to the WECS; that is,

$$
u(t)=u_{M P C}^{*}\left(t \mid t_{k}\right), \forall t \in\left[t_{k}, t_{k+1}\right) .
$$

At the next sampling time, the MPC optimization problem is re-evaluated.

\subsection{Economic MPC}

In the tracking MPC, the optimal operating references depend on both the operating region and the wind speed. When wind speed changes, the cost function Equation (33a) in tracking MPC may switch frequently according to operating regions. EMPC provides a unified framework for the optimal operation of WECS systems. The division of the entire operating region into subregions for controller design is no longer necessary as long as a unified economic cost function exists for the entire operating region, which is indeed the case for WECS systems. The proposed EMPC strategy can be formulated as the following scheme:

$$
\begin{gathered}
\min _{u(\tau) \in S(\triangle t), \varepsilon_{P}, \varepsilon_{\omega}, \varepsilon_{T}} \int_{t_{k}}^{t_{k}+N}\left(F_{E M P C}(x(\tau), u(\tau), v(\tau))+F_{S}\left(\varepsilon_{P}, \varepsilon_{\omega}, \varepsilon_{T}\right)\right) d \tau, \\
\text { s.t. Equation (33b) - Equation (33i). }
\end{gathered}
$$

In the above EMPC optimization problem, $F_{E M P C}$ represents the economic stage cost related to the economics of the operation and $F_{S}$ is the penalty on the slack variables as in the tracking MPC design. Two different designs of $F_{E M P C}$ are considered:

$$
\begin{aligned}
& F_{E M P C_{1}}(x(\tau), u(\tau), v(\tau))=-q^{E M P C_{1}} P_{e}(\tau)+r^{E M P C_{1}} \dot{\theta}^{2}(\tau), \\
& F_{E M P C_{2}}(x(\tau), u(\tau), v(\tau))=-q^{E M P C_{2}} P_{a}(\tau)+r^{E M P C_{2}} \dot{\theta}^{2}(\tau) .
\end{aligned}
$$

$F_{E M P C_{1}}$ means maximizing the produced electrical power while $F_{E M P C_{2}}$ trends to maximize aerodynamic power extracted from the wind turbine. Both stage costs account for structural fatigue. The two stage costs only differ in the first term. An interpretation of the impact of this difference over one prediction horizon is provided below. Let us define $L_{E M P C_{1}}$ and $L_{E M P C_{2}}$ as follows:

$$
\begin{gathered}
L_{E M P C_{1}}=\int_{t}^{t_{k}+N}-P_{e}(x(\tau)) d \tau, \\
L_{E M P C_{2}}=\int_{t}^{t_{k}+N}-\eta P_{a}(x(\tau), v(\tau)) d \tau,
\end{gathered}
$$

where $\eta$ is the efficiency of power conversion defined in Equation (16). Given that the aerodynamic power $P_{a}=T_{a} \omega_{a}$ and electrical power $P_{e}=\eta T_{g} \omega_{g}$, combining with Equations (9), (11) and (12), the difference between Equations (40) and (41) can be expressed as:

$$
\begin{aligned}
L_{E M P C_{2}}= & L_{E M P C_{1}}-\eta J_{a} \omega_{a}^{2}\left(t_{k}+N\right)-\eta J_{g} \omega_{g}^{2}\left(t_{k}+N\right)-\eta k_{s} \theta^{2}\left(t_{k}+N\right) \\
& -\eta \int_{t}^{t_{k}+N} d_{s} \dot{\theta}(\tau)^{2} d \tau+\text { constant. }
\end{aligned}
$$

In Equation (42), the three terms $\omega_{a}^{2}\left(t_{k}+N\right), \omega_{g}^{2}\left(t_{k}+N\right)$ and $\theta^{2}\left(t_{k}+N\right)$ stand for the terminal states of the system. In addition, the term $\int_{t}^{t_{k}+N} d_{s} \dot{\theta}(\tau)^{2} d \tau$ accounts for the drivetrain shaft transient load (i.e., fatigue). Equation (42) indicates that the EMPC with the stage cost Equation (38) (denoted as 
$\mathrm{EMPC}_{2}$ ) contains terminal cost terms inherently while the EMPC with stage cost Equation (39) (denoted as $\mathrm{EMPC}_{1}$ ) does not inherently contain terminal penalties. It can also tell from a practical point of view, a part of aerodynamic power $P_{a}$ is transformed to electrical power $P_{e}$, and the rest is stored in the equipment (i.e., the terminal cost in Equation (42)). Therefore, EMPC $_{1}$ may need a larger predictive horizon than $\mathrm{EMPC}_{2}$. On the other hand, $\mathrm{EMPC}_{2}$ may lead to increased drivetrain shaft transient load compared with $\mathrm{EMPC}_{1}$ given that the other control settings are the same. The derivation details can be found in Appendix A.

\section{Simulation Results and Discussion}

In this section, we carry out simulations to compare the classical tracking MPC and the EMPC in terms of closed-loop economic performance, i.e., the captured aerodynamic power $P_{a}$, the generated electrical power $P_{e}$ and the drivetrain shaft transient load $\dot{\theta}$. Two cases containing perfect wind speed information and inaccurate wind speed information are considered under different types of wind, i.e., gradient wind and turbulent wind.

\subsection{Simulation Settings}

In the simulations, the wind speed is generated according to the Van der Hoven spectrum [2]; that is, the wind speed is modeled as a slowly varying average wind speed superimposed by a rapidly varying turbulent wind speed:

$$
v=v_{m}+v_{d}
$$

where $v_{m}$ is the mean wind speed over a certain time period and $v_{d}$ is the rapid varying component. It is assumed that the current wind speed at the rotor can be measured, for example, using a light detection and ranging (LIDAR) system [28].

The performance of the control schemes will be compared under two types of wind: gradient wind and turbulent wind. Three controllers, i.e., the classical tracking MPC, EMPC 1 with stage cost Equation (38) and $\mathrm{EMPC}_{2}$ with stage cost Equation (39) are implemented in MATLAB (version 2017b). The dynamic optimization problems are solved using IPOPT based on Casadi (version 3.3) - a software framework to facilitate the implementation and solution to optimal control problems using automatic differentiation $[29,30]$. Moreover, control parameters used in the simulation are listed in Table 2 . The same weights are set for the stage costs of the two EMPC controllers. In order to get better performance for the classical tracking MPC, we choose different weights for partial load region(subregions I, II, III) and full load region (subregion IV). The horizon (prediction and control) for both MPC and EMPCs is fixed at $20 \mathrm{~s}$ with a sampling time of $0.1 \mathrm{~s}$.

Table 2. Controller settings.

\begin{tabular}{cc}
\hline Control Schemes & Parameters \\
\hline EMPC $_{1}$ & $q^{E M P C_{1}}=10, r^{E M P C_{1}}=2, r^{s}=1 e 8$ \\
EMPC $_{2}$ & $q^{E M P C_{2}}=10, r^{E M P C_{2}}=2, r^{s}=1 e 8$ \\
MPC (Partial load) & $q_{1}^{M P C}=5 e 6, q_{2}^{M P C}=2 e 3$, \\
& $q_{3}^{M P C}=3 e 8, r^{M P C}=2, r^{s}=1 e 8$ \\
MPC (Full load) & $q_{1}^{M P C}=5 e 5, q_{2}^{M P C}=2 e 3$, \\
& $q_{3}^{M P C}=7 e 5, r^{M P C}=2, r^{s}=1 e 8$ \\
Prediction horizon & $N=20 s$ \\
Controller sampling time & $\Delta t=0.1 s$ \\
\hline
\end{tabular}

\subsection{Perfect Information Scenario}

In the first scenario, we compare the three controllers when the information of wind speed is available along the predictive horizon and it is assumed that the wind speed is accurately known. 


\subsubsection{Gradient Wind}

In the first set of simulations, we consider the wind speed varies between two subregions and the wind is considered to be gradient wind. Figure 6 shows the wind speed used in this set of simulations. The wind speed jumps between $6.5,8$ and $12 \mathrm{~m} / \mathrm{s}$. This makes the system switches between subregion II, III and IV.

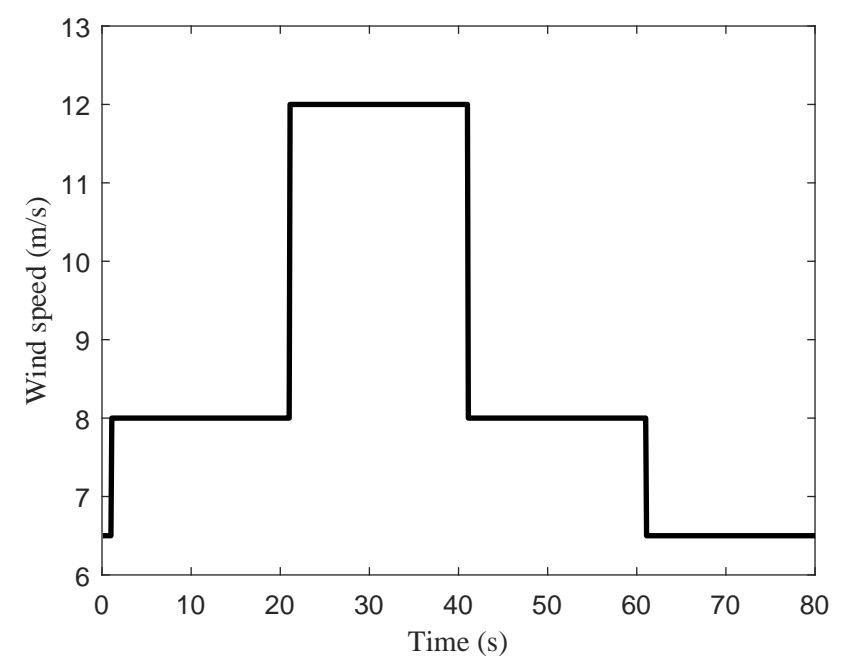

Figure 6. Wind speed.

The simulation results are shown in Figures 7 and 8. The blue lines are the references which are calculated for the classical tracking MPC using Equation (32). From the figures, it can be seen that when wind speed changes from $6.5 \mathrm{~m} / \mathrm{s}$ to $8 \mathrm{~m} / \mathrm{s}$, the system is operated in subregions II and its main objective is to extract wind power as much as possible. As shown in Figures 7 and 8, the tracking MPC and the two EMPCs all can track the optimal operating references. The tracking MPC and the two EMPCs give nearlv the same dvnamic traiectorv.
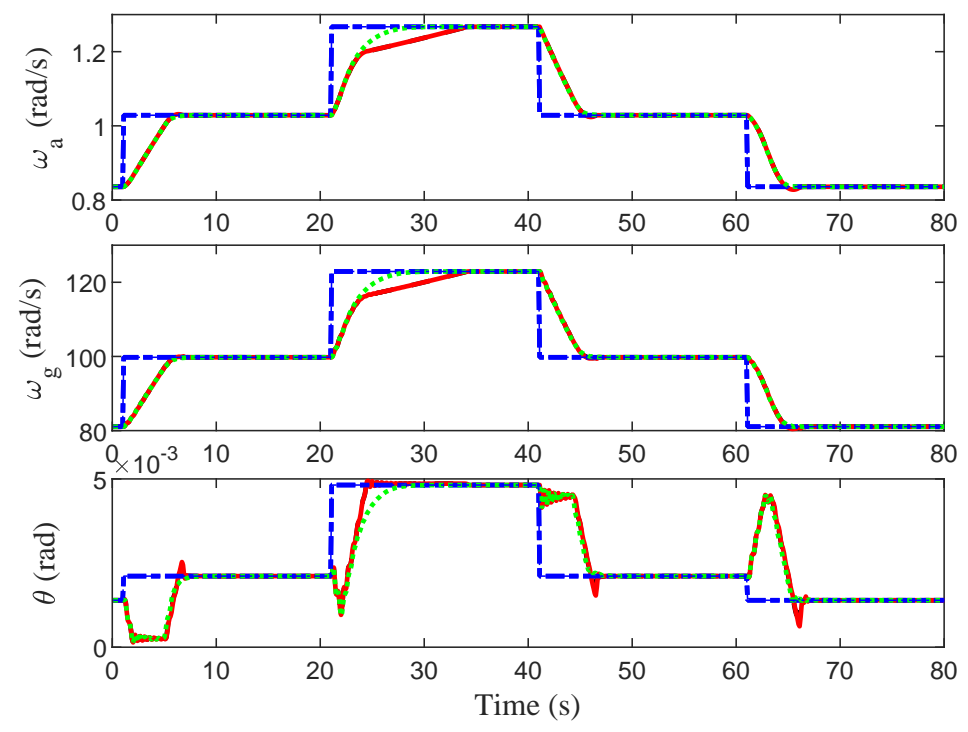

Figure 7. States $\omega_{a}, \omega_{g}$ and $\theta$ for the proposed $\mathrm{EMPC}_{1}$ (black dash-dotted line), $\mathrm{EMPC}_{2}$ (red solid line) and classical tracking MPC (green dashed line) under gradient wind. 
However, when the wind speed changes between $8 \mathrm{~m} / \mathrm{s}$ and $12 \mathrm{~m} / \mathrm{s}$ (switches between subregion III and subregion IV), the two EMPCs present much superior performance than the tracking MPC. As can be seen in Figure 8, the blade pitch angle $\beta$ under the tracking MPC approaches the optimal steady state gradually after the wind speed becomes $12 \mathrm{~m} / \mathrm{s}$; in contrast, the proposed EMPCs keep the pitch angle at zero for some time so that more energy from the wind can be captured. The behavior of EMPCs may be explained using $C_{p}$. In Figure 9, the black point is the highest value of $C_{p}$ which is the optimal operation point for wind turbine with partial load (subregions I, II, III). The red line indicates the optimal $C_{p}$ when the wind speed is over the rated value (subregion IV). When the wind speed changes from $8 \mathrm{~m} / \mathrm{s}$ to $12 \mathrm{~m} / \mathrm{s}$, the optimal $C_{p}$ is changed from the black point to a point on the red line. When using EMPCs, the pitch angle goes along the line $\beta=0$ and then along the red line. That is why the pitch angle keeps at zero for a while. However, as for the tracking MPC, it drives the system to the final optimal $C_{p}$ on the red line directly, which leads to decreased transient performance. The superiority of EMPCs over the tracking MPC can also be seen when the wind speed decreases from $12 \mathrm{~m} / \mathrm{s}$ to $8 \mathrm{~m} / \mathrm{s}$. In this case, the pitch angle has a smaller move under the EMPCs as shown in Figure 8, which can also be explained using Figure 9 similarly.
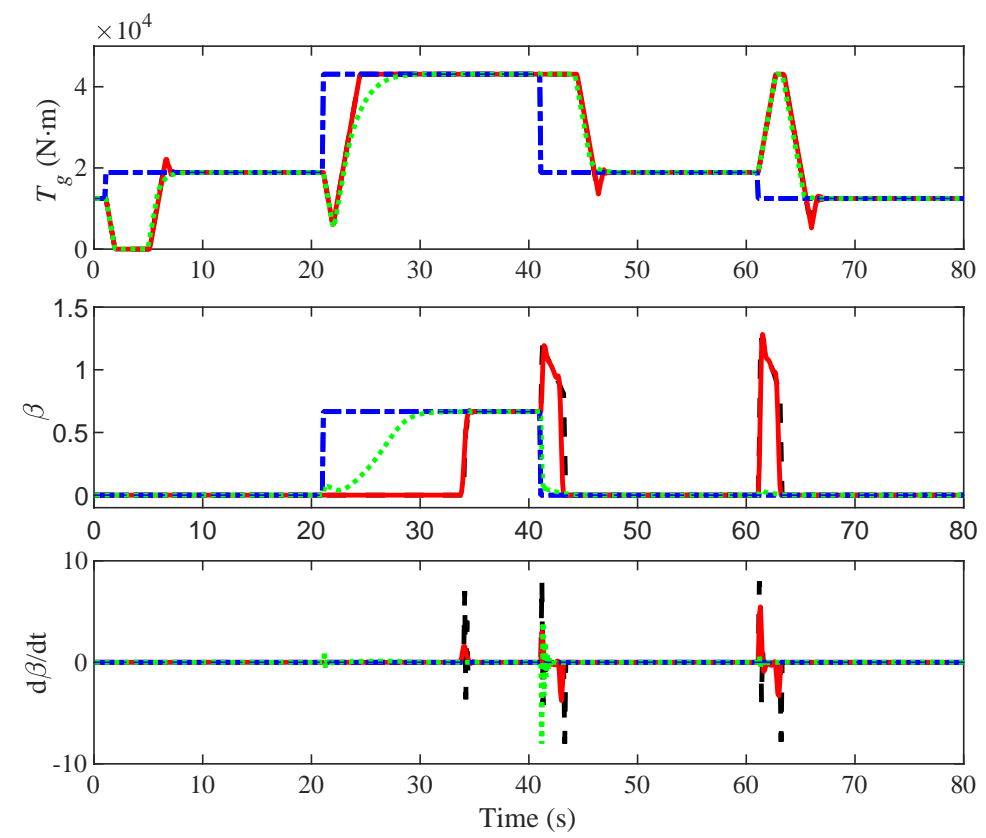

Figure 8. States $T_{g}, \beta$ and $d \beta / d t$ for the proposed $\mathrm{EMPC}_{1}$ (black dash-dotted line), $\mathrm{EMPC}_{2}$ (red solid line) and classical tracking MPC (green dashed line) under gradient wind.

The produced electrical power $P_{e}$ and aerodynamic power coefficient $C_{p}$ under the three controllers are shown in Figure 10. Apparently, in the transient period, the two EMPCs lead to a larger $C_{p}$, and the produced electrical power $P_{e}$ is also more than the classical tracking MPC. As for the case of wind speed decreasing, it extracts more wind energy using EMPCs at the cost of an action of blade pitch actuator. 


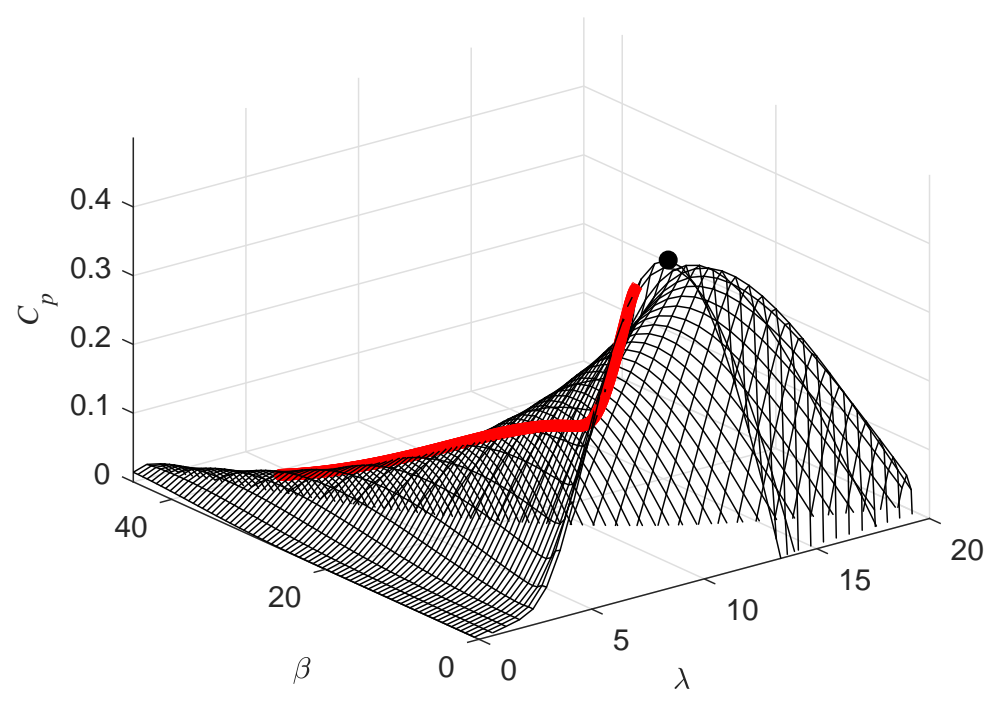

Figure 9. Three-dimensional graph of $C_{p}$.
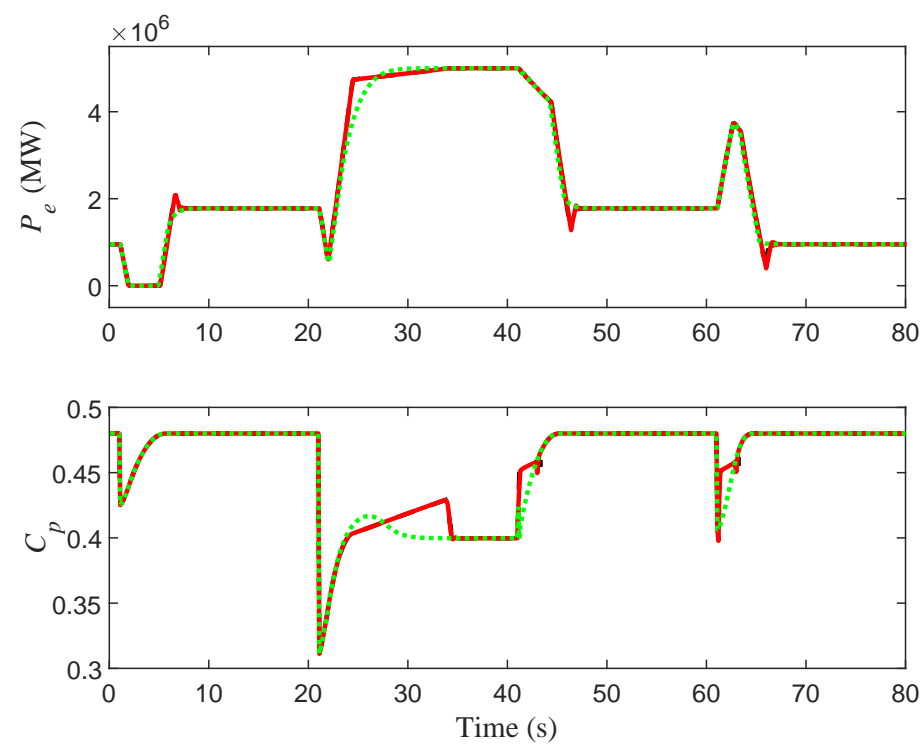

Figure 10. Performance $C_{p}$ and $P_{e}$ for the proposed $\mathrm{EMPC}_{1}$ (black dash-dotted line), $\mathrm{EMPC}_{2}$ (red solid line) and classical tracking MPC (green dashed line) under gradient wind.

For the sake of showing the performance of the control schemes quantitatively, the economic performance is evaluated in terms of the average power $T_{P_{e}}$ and average captured power $T_{P_{a}}$ defined as follows:

$$
T_{P_{e}}=\frac{1}{N s i m} \sum_{i=1}^{N s i m} P_{e}(i), T_{P_{a}}=\frac{1}{N s i m} \sum_{i=1}^{N s i m} P_{a}(i),
$$

where Nsim is the amount of simulation steps. The comparison results are listed in Table 3.

The numbers in brackets denote the ratios of the corresponding performance values with respect to the one of the tracking MPC. It is clearly shown that the two EMPCs give improved performance in terms of $T_{P_{e}}$ and $T_{P_{a}}$ in all cases. Especially in the switching process, the power captured by EMPCs compared with the MPC increases by $2.08 \%$ at the cost of slightly increased structural fatigue load. 
Table 3. Average economic performance under gradient wind.

\begin{tabular}{|c|c|c|c|c|}
\hline$\times 10^{6}$ & $6.5-8 \mathrm{~m} / \mathrm{s}$ & $8-12 \mathrm{~m} / \mathrm{s}$ & $12-8 \mathrm{~m} / \mathrm{s}$ & $8-6.5 \mathrm{~m} / \mathrm{s}$ \\
\hline$T_{P_{e}}^{E M P C_{1}}$ & $1.3934(1.00364)$ & $4.4570(1.0193)$ & $2.3421(1.0036)$ & $1.3214(1.0027)$ \\
\hline$T_{P_{e}}^{E M P C_{2}}$ & $1.3934(1.00364)$ & $4.4638(1.0208)$ & $2.3421(1.0036)$ & $1.3214(1.0027)$ \\
\hline$T_{P_{e}}^{M P C}$ & 1.3883 & 4.3727 & 2.3337 & 1.3178 \\
\hline$T_{P_{a}}^{E M P C_{1}}$ & $1.8664(1)$ & $5.3355(1.0184)$ & $1.871(1.0048)$ & $1.0034(1.0038)$ \\
\hline$T_{P_{a}}^{E M P C_{2}}$ & $1.8664(1)$ & $5.3355(1.0184)$ & $1.8713(1.0048)$ & $1.0034(1.0038)$ \\
\hline$T_{P_{a}}^{M P C}$ & 1.8664 & 5.239 & 1.862 & 0.9997 \\
\hline
\end{tabular}

\subsubsection{Turbulent Wind}

In the second set of simulations, we consider the performance of the three control schemes when we have turbulent wind. The turbulent wind sequence used in simulations is at an average value of $8 \mathrm{~m} / \mathrm{s}$ and $11 \mathrm{~m} / \mathrm{s}$ with the same medium turbulence intensity of $\mathrm{I}=0.15$ [2] shown in Figure 11 . In this case, we assume that we could obtain all the wind speed information on the whole prediction horizon for controllers. The simulation results for this turbulent wind speed are given in Figures 12-14. From the figures, it can be seen that there is no obvious superiority for the EMPCs in the partial load region. The produced electrical power $P_{e}$ and extracted aerodynamic power $P_{a}$ are almost the same while the fatigue load for EMPCs may get better than the classical tracking MPC. However, when the wind speed rapidly varies around the rated wind speed, the EMPCs give much superior performance over the tracking MPC. In this situation, the classical tracking MPC needs to change its set-points and weights constantly. We could see this impact from Figure 13. The change frequency of blade pitch angle for MPC strategy is higher than the EMPCs significantly.

In addition, further comparisons are also carried out to study the effects of prediction horizon on these controllers under this turbulent wind. Since the wind is fluctuating constantly, we consider structural fatigue defined as:

$$
T_{\text {Load }}=\frac{1}{N \operatorname{sim}} \sum_{i=1}^{N \operatorname{sim}} \dot{\theta}^{2}(i)
$$

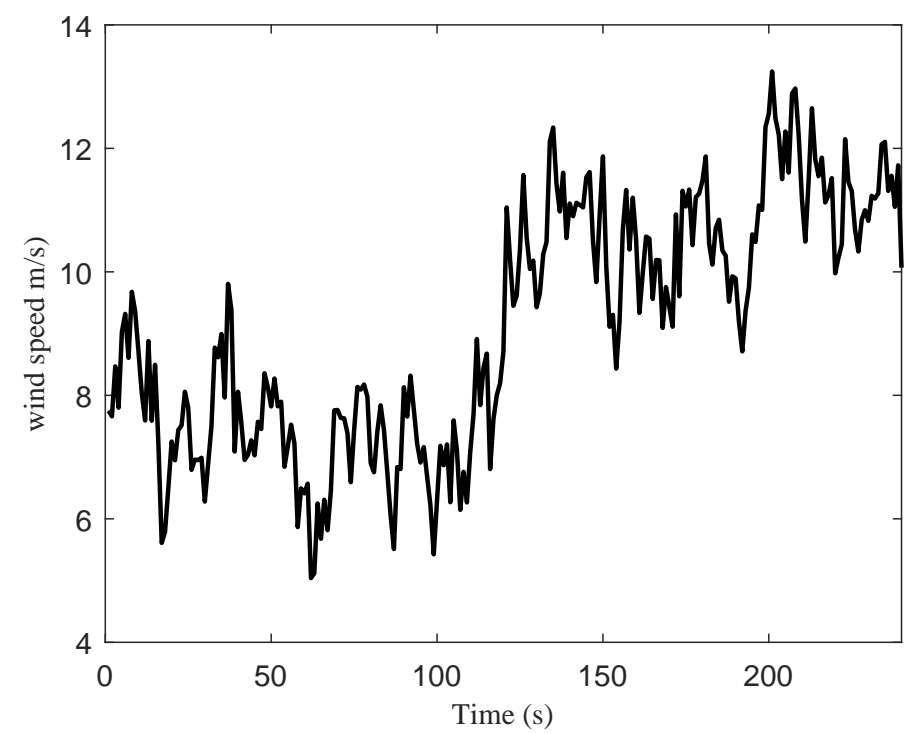

Figure 11. Wind speed.

The results are listed in Tables 4 and 5 with different prediction horizons obtained by simulating the system in a closed loop for $25 \mathrm{~min}$. From the tables, it can be seen that the captured aerodynamic power decreases with the decrease of the prediction horizon. When the prediction horizon is too short, 
EMPC $_{1}$ may even lose its ability to keep the system close to the optimal operating points as seen in Table 5. As for $\mathrm{EMPC}_{2}$, it still performs better with this short prediction horizon since it contains terminal cost in its objective shown in Equation (42). Moreover, the power captured by the EMPCs are about $2 \%$ more than that captured by the tracking MPC when $N$ is $20 \mathrm{~s}$. Furthermore, EMPCs get lower fatigue than MPC. In addition, it is consistent as shown in Equation (42) that $\mathrm{EMPC}_{1}$ gets better performance in mitigating drivetrain shaft transient loads than $\mathrm{EMPC}_{2}$.
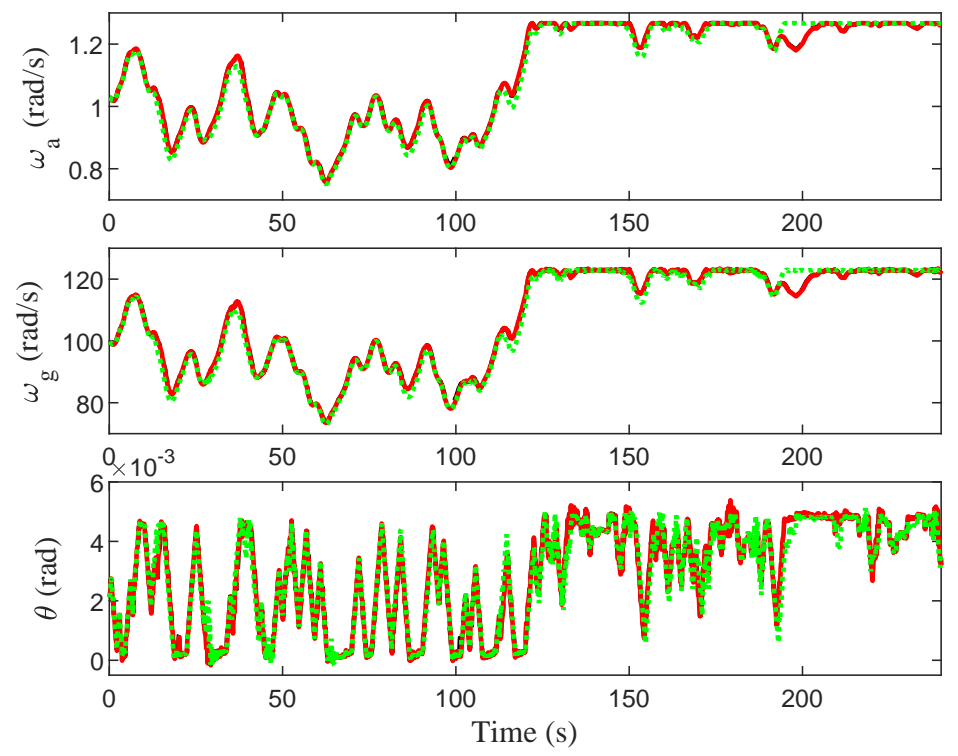

Figure 12. States $\omega_{a}, \omega_{g}$ and $\theta$ for the proposed $\mathrm{EMPC}_{1}$ (black dash-dotted line), $\mathrm{EMPC}_{2}$ (red solid line) and classical tracking MPC (green dashed line) under turbulent wind.
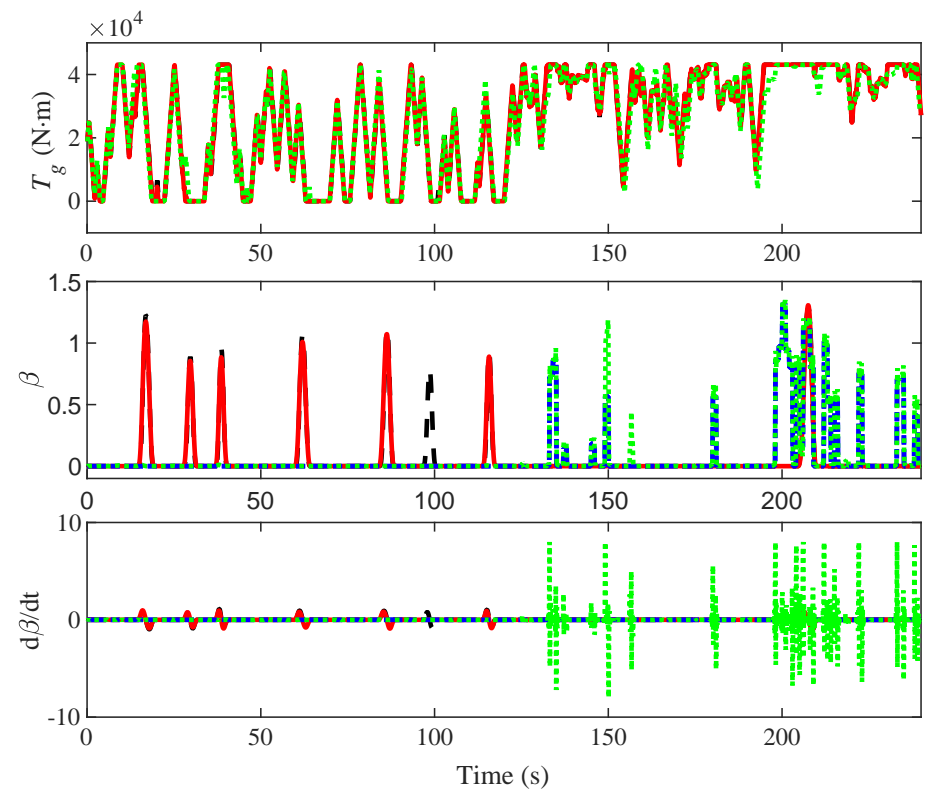

Figure 13. States $T_{g}, \beta$ and $d \beta / d t$ for the proposed $\mathrm{EMPC}_{1}$ (black dash-dotted line), $\mathrm{EMPC}_{2}$ (red solid line) and classical tracking MPC (green dashed line) under turbulent wind. 

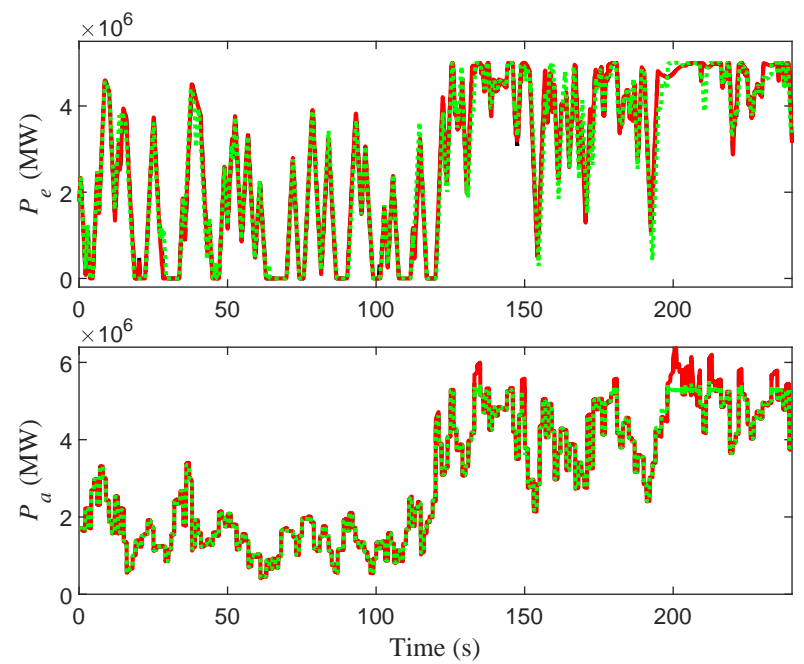

Figure 14. Performance $P_{e}$ and $P_{a}$ for the proposed EMPC 1 (black dash-dotted line), EMPC 2 (red solid line) and classical tracking MPC (green dashed line) under turbulent wind.

Table 4. Average economic performance for different prediction horizon at an average wind speed of $8 \mathrm{~m} / \mathrm{s}$.

\begin{tabular}{ccccc}
\hline $\mathbf{8} \mathbf{~ m} / \mathbf{s}$ & $N=\mathbf{2 0 ~ s}$ & $N=\mathbf{1 5} \mathbf{s}$ & $N=\mathbf{1 0} \mathbf{s}$ & $N=\mathbf{8 ~ s}$ \\
\hline$T_{P_{e}}^{E M P C_{1}}$ & $1.3276 \times 10^{6}$ & $1.3276 \times 10^{6}$ & $1.3228 \times 10^{6}$ & $1.315 \times 10^{6}$ \\
$T_{P_{e}}^{E M P C_{2}}$ & $1.3261 \times 10^{6}$ & $1.3261 \times 10^{6}$ & $1.326 \times 10^{6}$ & $1.3261 \times 10^{6}$ \\
$T_{P_{e}}^{M P C}$ & $1.3249 \times 10^{6}$ & $1.3249 \times 10^{6}$ & $1.3249 \times 10^{6}$ & $1.3248 \times 10^{6}$ \\
\hline$T_{P_{a}}^{E M P C_{1}}$ & $1.4026 \times 10^{6}$ & $1.4026 \times 10^{6}$ & $1.3974 \times 10^{6}$ & $1.3891 \times 10^{6}$ \\
$T_{P_{a}}^{E M P C_{2}}$ & $1.4013 \times 10^{6}$ & $1.4013 \times 10^{6}$ & $1.4013 \times 10^{6}$ & $1.4012 \times 10^{6}$ \\
$T_{P_{a}}^{M M P C}$ & $1.3999 \times 10^{6}$ & $1.3999 \times 10^{6}$ & $1.3999 \times 10^{6}$ & $1.3998 \times 10^{6}$ \\
\hline$T_{\text {Load }}^{E M P C_{1}}$ & 0.0048 & 0.0048 & 0.0048 & 0.0045 \\
$T_{\text {Load }}^{E M P C_{2}}$ & 0.0059 & 0.0059 & 0.0059 & 0.0060 \\
$T_{\text {Load }}^{M P C}$ & 0.0073 & 0.0073 & 0.0074 & 0.0073 \\
\hline
\end{tabular}

Table 5. Average economic performance for different prediction horizon at an average wind speed of $11 \mathrm{~m} / \mathrm{s}$.

\begin{tabular}{ccccc}
\hline $\mathbf{1 1} \mathbf{~ m} / \mathbf{s}$ & $N=\mathbf{2 0 ~ s}$ & $N=\mathbf{1 5} \mathbf{s}$ & $N=\mathbf{1 0} \mathbf{s}$ & $N=\mathbf{8 ~ s}$ \\
\hline$T_{P_{e}}^{E M P C_{1}}$ & $3.8701 \times 10^{6}$ & $3.8644 \times 10^{6}$ & $3.4858 \times 10^{6}$ & $3.0743 \times 10^{6}$ \\
$T_{P_{e}}^{E M P C_{2}}$ & $3.8701 \times 10^{6}$ & $3.8601 \times 10^{6}$ & $3.8288 \times 10^{6}$ & $3.8269 \times 10^{6}$ \\
$T_{P_{e}}^{M P C}$ & $3.793 \times 10^{6}$ & $3.793 \times 10^{6}$ & $3.793 \times 10^{6}$ & $3.7928 \times 10^{6}$ \\
\hline$T_{P_{a}}^{E M P C_{1}}$ & $4.0924 \times 10^{6}$ & $4.0922 \times 10^{6}$ & $3.6867 \times 10^{6}$ & $3.2482 \times 10^{6}$ \\
$T_{P_{a}}^{E M P C_{2}}$ & $4.0924 \times 10^{6}$ & $4.0913 \times 10^{6}$ & $4.051 \times 10^{6}$ & $4.0491 \times 10^{6}$ \\
$T_{P_{a}}^{M P C}$ & $4.013 \times 10^{6}$ & $4.013 \times 10^{6}$ & $4.013 \times 10^{6}$ & $4.0128 \times 10^{6}$ \\
\hline$T_{\text {Load }}^{E M P C_{1}}$ & 0.0013 & $9.06 \mathrm{e}-4$ & $3.6 \mathrm{e} 0-4$ & $3.6 \mathrm{e} 0-4$ \\
$T_{\text {Load }}^{E M P C_{2}}$ & 0.0017 & 0.0016 & 0.0017 & 0.0017 \\
$T_{\text {Load }}^{M P C}$ & 0.0022 & 0.0022 & 0.0022 & 0.0022 \\
\hline
\end{tabular}




\subsection{Uncertain Information Scenario}

In Section 4.2, all the wind speed information on the whole prediction horizon for controllers design is assumed to be available. In this section, we will compare the economic performance of the two EMPCs and the tracking MPC with a limited wind speed preview horizon which is possibly shorter than the prediction horizon. The simulation results are listed in Tables 6 and 7. Ninf stands for the limited wind speed preview horizon. We only show the ratio of the performance values of the EMPCs to the tracking MPC here for brevity. It can be seen that a limited wind speed preview has unfortunately a non-negligible effect on economic performance of all three controllers, especially the EMPCs. If only the current wind speed is available, EMPCs perform no superiority over the tracking MPC in the entire operation region.

Table 6. The rate of EMPCs to MPC with a limited preview horizon at an average wind speed of $8 \mathrm{~m} / \mathrm{s}$.

\begin{tabular}{cccc}
\hline $\mathbf{8} \mathbf{~ m} / \mathbf{s}$ & Ninf $=\mathbf{1 5} \mathbf{s}$ & Ninf $=\mathbf{5} \mathbf{s}$ & Ninf $=$ Current \\
\hline$T_{P_{e}}^{E M P C_{1}}$ & $99.91 \%$ & $99.90 \%$ & $99.78 \%$ \\
$T_{P_{e}}^{E M P C_{2}}$ & $99.92 \%$ & $99.90 \%$ & $99.71 \%$ \\
$T_{P_{a}}^{E M P C_{1}}$ & $100.00 \%$ & $99.99 \%$ & $99.86 \%$ \\
$T_{P_{a}}^{E M P C_{2}}$ & $100.01 \%$ & $100.00 \%$ & $99.82 \%$ \\
$T_{\text {Load }}^{E M C_{1}}$ & $69.91 \%$ & $71.19 \%$ & $92.73 \%$ \\
$T_{\text {Load }}^{E M P C_{2}}$ & $82.90 \%$ & $86.13 \%$ & $102.01 \%$ \\
\hline
\end{tabular}

Table 7. The rate of EMPCs to MPC with a limited preview horizon at an average wind speed of $11 \mathrm{~m} / \mathrm{s}$.

\begin{tabular}{cccc}
\hline $\mathbf{1 1} \mathbf{~ m} / \mathbf{s}$ & Ninf $=\mathbf{1 5} \mathbf{s}$ & Ninf $=\mathbf{5} \mathbf{s}$ & Ninf $=$ Current \\
\hline$T_{P_{e}}^{E M P C_{1}}$ & $102.26 \%$ & $101.26 \%$ & $94.54 \%$ \\
$T_{P_{e}}^{E M P C_{2}}$ & $101.54 \%$ & $101.26 \%$ & $92.03 \%$ \\
$T_{P_{a}}^{E M P C_{1}}$ & $101.49 \%$ & $101.22 \%$ & $94.46 \%$ \\
$T_{P_{a}}^{E M P C_{2}}$ & $101.49 \%$ & $100.21 \%$ & $91.97 \%$ \\
$T_{\text {Load }}^{E M P C_{1}}$ & $77.50 \%$ & $73.78 \%$ & $130.30 \%$ \\
$T_{\text {Load }}^{E M P C_{2}}$ & $96.84 \%$ & $95.71 \%$ & $147.66 \%$ \\
\hline
\end{tabular}

Furthermore, we have considered the effects of wind speed measurement noise on the controller performance and the results are shown in Tables 8 and 9. In the tables, $\sigma$ stands for the standard deviation of wind speed noise. From the results, it can be seen that the measurement noise also negatively affects the control performance of all the controllers. When measurement noise is present, the two EMPCs may give worse performance then the tracking MPC. From the above simulations, we can see the potential of EMPCs to significantly improve the operation of wind turbines if the wind speed can be measured and predicted accurately. 
Table 8. The rate of EMPCs to MPC with wind speed noise at an average wind speed of $8 \mathrm{~m} / \mathrm{s}$.

\begin{tabular}{cccc}
\hline $\mathbf{8} \mathbf{~ m} / \mathbf{s}$ & $\boldsymbol{\sigma}=\mathbf{0 . 2}$ & $\boldsymbol{\sigma}=\mathbf{0 . 5}$ & $\boldsymbol{\sigma}=\mathbf{1}$ \\
\hline$T_{P_{e}}^{E M P C_{1}}$ & $99.80 \%$ & $99.61 \%$ & $97.86 \%$ \\
$T_{P_{e}}^{E M P C_{2}}$ & $99.81 \%$ & $99.61 \%$ & $98.13 \%$ \\
$T_{P_{a}}^{E M P C_{1}}$ & $99.88 \%$ & $99.71 \%$ & $97.89 \%$ \\
$T_{P_{a}}^{E M P C_{2}}$ & $99.92 \%$ & $99.77 \%$ & $98.11 \%$ \\
$T_{\text {Load }}^{E M P C_{1}}$ & $57.88 \%$ & $77.68 \%$ & $77.95 \%$ \\
$T_{\text {Load }}^{E M P C_{2}}$ & $79.94 \%$ & $86.08 \%$ & $103.67 \%$ \\
\hline
\end{tabular}

Table 9. The rate of EMPCs to MPC with wind speed noise at an average wind speed of $11 \mathrm{~m} / \mathrm{s}$.

\begin{tabular}{cccc}
\hline $\mathbf{1 1} \mathbf{~} / \mathbf{s}$ & $\boldsymbol{\sigma}=\mathbf{0 . 2}$ & $\boldsymbol{\sigma}=\mathbf{0 . 5}$ & $\boldsymbol{\sigma}=\mathbf{1}$ \\
\hline$T_{P_{e}}^{E M P C_{1}}$ & $101.23 \%$ & $99.29 \%$ & $98.36 \%$ \\
$T_{P_{e}}^{E M P C_{2}}$ & $99.39 \%$ & $97.24 \%$ & $95.16 \%$ \\
$T_{P_{a}}^{E M P C_{1}}$ & $101.13 \%$ & $99.52 \%$ & $98.88 \%$ \\
$T_{P_{a}}^{E M P C_{2}}$ & $99.34 \%$ & $97.46 \%$ & $95.63 \%$ \\
$T_{\text {Load }}^{E M P C_{1}}$ & $77.50 \%$ & $89.02 \%$ & $121.83 \%$ \\
$T_{\text {Load }}^{E M P C_{2}}$ & $96.84 \%$ & $124.59 \%$ & $166.93 \%$ \\
\hline
\end{tabular}

\subsection{Computational Times}

In another set of simulations, we evaluate the computational times of the two EMPCs and the tracking MPC. One hundred simulations have been run using different wind profiles and using both the EMPCs and the tracking MPC. Different prediction horizons are also considered.

The relative computational times of the two EMPCs and the tracking MPC to the computational time of a linear MPC are shown in Figure 15. From the figure, it can be seen that EMPC 2 is more $^{2}$ computationally demanding. This may be due to the inclusion of the complicated aerodynamic power coefficient $C_{p}$ directly in the stage cost.

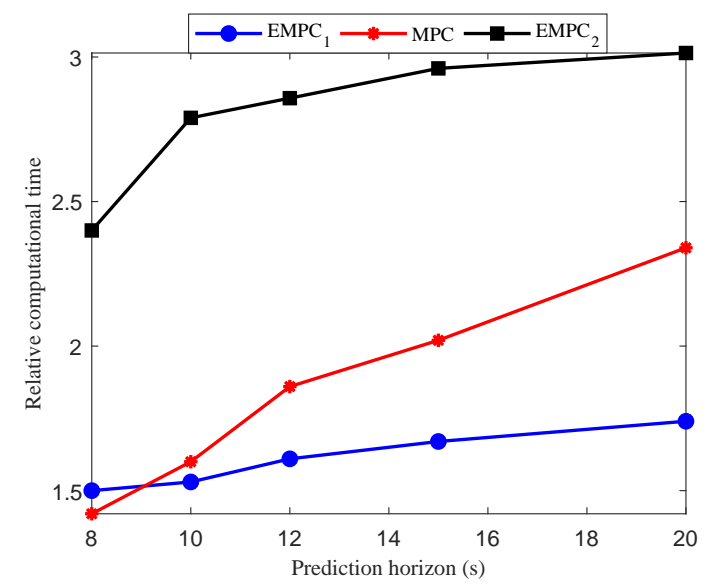

Figure 15. Computational time for different prediction horizons.

\section{Conclusions}

In this paper, we focused on the comparison of a classical tracking MPC and two EMPCs for a typical WECS. From the simulation results, we found that (a) when the WECS is operated in partial 
load subregions, the EMPCs and the tracking MPC may give similar performance; (b) when the WECS is operated in the transition between the operating modes (i.e., partial load mode and full load mode), the two EMPCs can improve the captured wind energy by about $2 \%$ in mode transitions which is comparable to other strategies [11,25]; (c) the two EMPCs can decrease the structural fatigue nearly by about $30 \%$ in the entire operating region; and (d) when there is uncertainty in wind speed prediction or measurement, the performance of all control schemes decrease and the EMPCs tend to be more sensitive to measurement noise. The relation between the two EMPCs was also investigated and the results were useful in explaining the different behaviors of the two EMPCs. In summary, EMPC is a promising optimal control strategy for WECSs and has the potential to significantly improve the energy extraction while reducing system fatigue. Future research topics include the design of EMPCs that is more robust to measurement noise and uncertainty in wind speed prediction.

Author Contributions: Conceptualization, J.C. and J.L.; Methodology, J.C. and S.L.; Software, J.C.; Writing-Original Draft Preparation, J.C.; Writing-Review and Editing, J.L.; Supervision, J.L. and X.L.; Project Administration, J.L. and X.L.

Funding: This research was funded by the Natural Sciences and Engineering Research Council of Canada (NSERC) Grant No. RGPIN 435767; the China Scholarship Council (CSC); the National Natural Science Foundation of China under Grant 61673171, U1709211, 61533013; and the Fundamental Research Funds for the Central Universities under Grant 2017ZZD004.

Conflicts of Interest: The authors declare no conflict of interest.

\section{Abbreviations}

The following abbreviations are used in this manuscript:

$\begin{array}{ll}\text { MPC } & \text { Model Predictive Control } \\ \text { EMPC } & \text { Economic Model Predictive Control } \\ \text { WECSs } & \text { Wind Energy Conversion Systems } \\ \text { MPPT } & \text { Maximum Power Point Tracking } \\ \text { NREL } & \text { National Renewable Energy Laboratory } \\ \text { TSR } & \text { Tip Speed Ratio } \\ \text { HCS } & \text { Hill-Climb Search } \\ \text { PI } & \text { Proportional Integral } \\ \text { LQR } & \text { Linear Quadratic Gaussian } \\ \text { LIDAR } & \text { Light Detection And Ranging }\end{array}$

\section{Appendix A}

Given that the aerodynamic power $P_{a}=T_{a} \omega_{a}$ and electrical power $P_{e}=\eta T_{g} \omega_{g}$, Equation (41) can be re-expressed as:

$$
L_{E M P C_{1}}-L_{E M P C_{2}}=\int_{t}^{t_{k}+N} \eta \omega_{a}(\tau) T_{a}(\tau)-\eta \omega_{g}(\tau) T_{g}(\tau) d \tau
$$

Combining with Equations (9), (11) and (12), it can be obtained that

$$
\begin{aligned}
L_{E M P C_{1}}-L_{E M P C_{2}}= & \eta \int_{t}^{t_{k}+N} J_{a} \omega_{a}(\tau) \dot{\omega}_{a}(\tau) d \tau+\eta \int_{t}^{t_{k}+N} J_{g} \omega_{g}(\tau) \dot{\omega}_{g}(\tau) d \tau \\
& +\eta \int_{t}^{t_{k}+N} k_{s} \theta(\tau) \dot{\theta}(\tau) d \tau+\eta \int_{t}^{t_{k}+N} d_{s} \dot{\theta}(\tau)^{2} d \tau \\
& =\eta J_{a} \omega_{a}^{2}\left(t_{k}+N\right)-\eta J_{a} \omega_{a}^{2}\left(t_{k}\right)+\eta J_{g} \omega_{g}^{2}\left(t_{k}+N\right)-\eta J_{g} \omega_{g}^{2}\left(t_{k}\right) \\
& +\eta k_{s} \theta^{2}\left(t_{k}+N\right)-\eta k_{s} \theta^{2}\left(t_{k}\right)+\eta \int_{t}^{t_{k}+N} d_{s} \dot{\theta}(\tau)^{2} d \tau .
\end{aligned}
$$

Since $\omega_{a}\left(t_{k}\right), \omega_{g}\left(t_{k}\right)$ and $\theta\left(t_{k}\right)$ are the initial conditions and may considered as constants, then Equation (42) is obtained. 


\section{References}

1. Doubrawa M.P.; Scott G.N.; Musial W.D.; Kilcher L.F. Offshore Wind Energy Resource Assessment for Alaska; National Renewable Energy Lab. (NREL): Golden, CO, USA, 2018.

2. Munteanu, I.; Cutululis, N.A.; Bratcu, A.I.; Ceanga, E. Optimal Control of Wind Energy Systems; Springer: Glasgow, UK, 2018; pp. 30-33.

3. Chen, Z.; Guerrero, J.M.; Blaabjerg, F. A Review of the State of the Art of Power Electronics for Wind Turbines. IEEE Trans. Power Electron. 2009, 24, 1859-1875. [CrossRef]

4. Zhao, Y.; Wei, C.; Zhang, Z.; Qiao, W. A Review on Position/Speed Sensorless Control for Permanent-Magnet Synchronous Machine-Based Wind Energy Conversion Systems. IEEE J. Emerg. Sel. Top. Power Electron. 2013, 1, 203-216. [CrossRef]

5. Mishra, Y.; Mishra, S.; Li, F.; Dong, Z.Y.; Bansal, R.C. Small-Signal Stability Analysis of a DFIG-Based Wind Power System Under Different Modes of Operation. IEEE Trans. Energy Convers. 2009, 24, $972-982$. [CrossRef]

6. Perng, J.-W.; Chen, G.-Y.; Hsieh, S.-C. Optimal PID Controller Design Based on PSO-RBFNN for Wind Turbine Systems. Energies 2014, 7, 191-209. [CrossRef]

7. Munteanu, L.; Cutululis, N.A.; Bratcu, A.L.; Ceanga, E. Optimization of variable speed wind power systems based on a LQG approach. Control Eng. Pract. 2005, 13, 903-912. [CrossRef]

8. Grimble, M.J. Two and a half degrees of freedom LQG controller and application to wind turbines. IEEE Trans. Autom. Control 2002, 39, 122-127. [CrossRef]

9. Ma, M.; Chen, H.; Liu, X.; Allgoewer, F. Moving horizon H-infinity control of variable speed wind turbines with actuator saturation. IET Renew. Power Gener. 2014, 8, 498-508. [CrossRef]

10. Moradi, H.; Vossoughi, G. Robust control of the variable speed wind turbines in the presence of uncertainties: A comparison between H-infinity and PID controllers. Energy 2015, 90, 1508-1521. [CrossRef]

11. Huang, C.; Li, F.; Jin, Z. Maximum Power Point Tracking Strategy for Large-Scale Wind Generation Systems Considering Wind Turbine Dynamics. IEEE Trans. Ind. Electron. 2015, 62, 2530-2539. [CrossRef]

12. Soliman, M.; Malik, O.P.; Westwick, D.T. Multiple Model Predictive Control for Wind Turbines With Doubly Fed Induction Generators. IEEE Trans. Sustain. Energy 2011, 2, 215-225. [CrossRef]

13. Song, D.; Yang, J.; Dong, M.; Joo, Y.H. Model predictive control with finite control set for variable-speed wind turbines. Energy 2017, 126, 564-572. [CrossRef]

14. Spencer, M.D.; Stol, K.A.; Unsworth, C.P.; Cater, J.E.; Norris, S.E. Model predictive control of a wind turbine using short-term wind field predictions. Wind Energy 2013, 16, 417-434. [CrossRef]

15. Lasheen, A.; Saad, M.S.; Emara, H.M.; Elshafei, A.L. Continuous-time tube-based explicit model predictive control for collective pitching of wind turbines. Energy 2017, 118, 1222-1233. [CrossRef]

16. Angeli, D.; Amrit, R.; Rawlings, J.B. On Average Performance and Stability of Economic Model Predictive Control. IEEE Trans. Autom. Control 2012, 57, 1615-1626. [CrossRef]

17. Heidarinejad, M.; Liu, J.; Christofides, P.D. Economic model predictive control of nonlinear process systems using Lyapunov techniques. AIChE J. 2012, 58, 855-870. [CrossRef]

18. Ellis, M.; Durand, H.; Christofides, P.D. A tutorial review of economic model predictive control methods. J. Process Control 2014, 24, 1156-1178. [CrossRef]

19. Zhang, X.; Bao, J.; Wang, R.; Zheng, C.; Skyllas-Kazacos, M. Dissipativity based distributed economic model predictive control for residential microgrids with renewable energy generation and battery energy storage. Renew. Energy 2017, 100, 18-34. [CrossRef]

20. Liu, S.; Liu, J. Economic model predictive control with extended horizon. Automatica 2016, 73, $180-192$. [CrossRef]

21. Zeng, J.; Liu, J. Economic Model Predictive Control of Wastewater Treatment Processes. Ind. Eng. Chem. Res. 2015, 54, 5710-5721. [CrossRef]

22. Liu, S.; Zhang, J.; Liu, J. Economic MPC with terminal cost and application to an oilsand primary separation vessel. Chem. Eng. Sci. 2015, 136, 27-37. [CrossRef]

23. Mao, Y.; Liu, S.; Nahar, J.; Liu, J.; Ding, F. Soil moisture regulation of agro-hydrological systems using zone model predictive control. Comput. Electron. Agric. 2018, 154, 239-247. [CrossRef]

24. Gros, S.; Schild, A. Real-time economic nonlinear model predictive control for wind turbine control. Int. J. Control 2017, 90, 2799-2812. [CrossRef] 
25. Shaltout, M.L.; Ma, Z.; Chen, D. An Adaptive Economic Model Predictive Control Approach for Wind Turbines. J. Dyn. Syst. Meas. Control 2018, 140. [CrossRef]

26. Gosk, A. Model Predictive Control of a Wind Turbine. Master's Thesis, Technical University of Denmark, Lyngby, Denmark, 2011.

27. Jonkman, J.; Butterfield, S.; Musial, W.; Scott, G. Definition of a 5-MW Reference Wind Turbine for Offshore System Development. In Office of Scientific Technical Information Technical Reports; National Renewable Energy Laboratory: Golden, CO, USA, 2009.

28. Schlipf, D.; Schlipf, D.J.; Kuehn, M. Nonlinear model predictive control of wind turbines using LIDAR. Wind Energy 2013, 16, 1107-1129. [CrossRef]

29. Andersson, J.A.E.; Gillis, J.; Horn, G.; Rawlings, J.B.; Diehl, M. CasADi: A software framework for nonlinear optimization and optimal control. Math. Program. Comput. 2018, 1-36. [CrossRef]

30. Decardi-Nelson, B.; Liu, S.; Liu, J. Improving Flexibility and Energy Efficiency of Post-Combustion $\mathrm{CO}_{2}$ Capture Plants Using Economic Model Predictive Control. Processes 2018, 6, 135. [CrossRef]

(C) 2018 by the authors. Licensee MDPI, Basel, Switzerland. This article is an open access article distributed under the terms and conditions of the Creative Commons Attribution (CC BY) license (http:/ / creativecommons.org/licenses/by/4.0/). 